\title{
VIVÊNCIAS DE FAMÍLIAS QUE ADOTARAM PRÉ-ADOLESCENTES E O MITO DA ADOÇÃO TARDIA
}

\author{
EXPERIENCES OF FAMILIES WHO ADOPTED ADOLESCENTS \\ AND THE MYTH OF LATE ADOPTION
}

\author{
Angela Morais Silva ${ }^{1}$ \\ Verônica Suzuki Kemmelmeier ${ }^{2}$
}

\begin{abstract}
RESUMO
O presente artigo trata da adoção de adolescentes na perspectiva da família adotante. Buscou-se, através da pesquisa, investigar quais são as principais motivações que impulsionaram a adoção de crianças que já ultrapassaram a segunda infância, avaliar como se deu este processo e qual vem a ser o perfil de família que busca este tipo de perfilhação. Trata-se de uma pesquisa empírica, realizada na modalidade de estudo de caso e fundamentada teoricamente por uma seletiva revisão bibliográfica. Foram realizadas entrevistas semi-estruturadas com duas famílias que adotaram, cada qual, um menino de onze anos. Uma vez coletadas as informações, as entrevistas foram transcritas e o conteúdo categorizado e posteriormente confrontado com o referencial teórico pesquisado. A análise permitiu identificar diferentes motivações para este tipo de adoção, além de revelar que a adoção é um processo gradual que demanda aceitação e diálogo e, ainda, que o perfil de família que efetiva essa modalidade de adoção condiz com o modelo nuclear. Acredita-se que uma maior compreensão das motivações e da dinâmica que rege essas famílias adotantes pode fomentar práticas que favoreçam o desenvolvimento ou fortalecimento de uma cultura de adoção que prestigie a adoção de crianças nessa faixa etária.
\end{abstract}

Palavras-chave: Adoção. Instituições de abrigo. Família adotante.

\begin{abstract}
This article discusses the adoption of adolescents from the perspective of the adopting family. The aim of the research was to investigate the main motivation for the adoption of teenagers, evaluate how this process happened and what the profile of the family who looks for older children is. It is an empirical research conducted in the form of a case study and theoretically grounded on a selective literature review. Semi-structured interviews were conducted with two families who adopted
\end{abstract}

\footnotetext{
${ }^{1}$ Docente colaboradora do Centro de Ciências Sociais Aplicadas da Universidade Estadual do Oeste do Paraná - UNIOESTE, campus de Francisco Beltrão. E-mail: angelynhamorais@gmail.com

${ }^{2}$ Docente efetiva do curso de Psicologia da Universidade Estadual do Centro-Oeste - UNICENTRO, campus de Irati. E-mail: eronicask@uol.com.br
} 
eleven year-old boys each. After the data collection, the interviews were transcribed and their contents categorized and later confronted with the theoretical framework. The analysis identified different motivations for this type of adoption; in addition to revealing that the adoption is a gradual process that demands acceptance and dialogue and also that the profile of the family who looks for this kind of adoption is consistent with the nuclear model. It is believed that a greater understanding of the motivations and dynamics governing these adopting families can promote practices that encourage the development or the strengthening of a culture of adoption of children of this age group.

Keywords: Adoption. Sheltering institutions. Adopting family.

\section{Introdução}

A adoção de crianças e adolescentes ainda constitui uma temática polêmica em torno da qual figuram mitos e preconceitos dos mais variados tipos. Como assinala Vargas (1998), a prática da adoção data de muito tempo, podendo-se inclusive afirmar que acompanha a história da própria humanidade, tendo evoluído de acordo com as transformações da família e dos papéis desempenhados no interior dessa instituição. No imaginário e no senso comum da sociedade é possível identificar muitas crenças envolvendo a prática de adotar crianças/adolescentes. Há, ainda, muito presente na atualidade, a preferência dos candidatos a pais adotivos por bebês recém-nascidos, em virtude da crença difundida de que crianças maiores já vêm com uma "bagagem" que pode prejudicar ou dificultar o processo de adaptação à nova família. É muito comum as pessoas associarem as condutas e comportamentos dessas crianças ao seu histórico, quase sempre marcado por situações de abandono, desamparo, violência ou negligência, experimentadas na família de origem ou na instituição de abrigo da qual possam ter advindo. Ebrahim (2001) considera a aceitação da história de vida e da herança biológica da criança por seus pais adotivos como condição fundamental para o sucesso da adoção.

Inevitavelmente, qualquer discussão em torno da adoção remete diretamente à questão do abandono. Muitos são os autores que proclamam a preponderância da presença da figura materna para o desenvolvimento do ser humano, como se esta fosse uma prescrição natural, inerente a um suposto "instinto materno". Entretanto, sabe-se que a materna- gem é uma construção social que se configura diferentemente de acordo com a cultura e com o período histórico. A partir da perspectiva de Böing (2004) acerca do abandono, é possível constatar que podem ser múltiplas as razões que levam uma pessoa a, deliberadamente, doar um filho. É frequente, no senso comum, a convicção de que o abandono de uma criança é uma escolha, uma atitude desumana e irresponsável. Porém, nem sempre a situação deve ser tão superficialmente abordada. Muitas vezes, mulheres grávidas e sem o apoio do pai da criança não suportam as pressões de uma sociedade que ainda rotula e estigmatiza as "mães solteiras" sendo que, não raro, essa situação está aliada a dificuldades financeiras, o que pode culminar na doação da prole. Há a necessidade de um olhar crítico para essas questões, buscando fugir à tendência de julgamentos precipitados.

No concernente à realidade brasileira, faz-se imprescindível avaliar em que medida a entrega de um filho para a adoção pode agregar um caráter de "escolha" por parte dos genitores. Costa e Campos (2003) questionam se há, de fato, liberdade para tal escolha e concluem que a alegação da falta de recursos materiais para a criação do filho como justificativa para entregá-lo à adoção tende a ser mais bem aceita pela sociedade: “[...] a própria sociedade que julga severamente a mãe que entrega ou abandona um filho, não se envergonha do fato desta mãe alegar agir assim em função da desigualdade social, da pobreza e ou de seu próprio abandono". (COSTA; CAMPOS, 2003, p. 223). São encaminhadas para a adoção crianças abandonadas ou que, por algum motivo muito forte, foram afastadas do convívio com a família de origem. Maus-tratos, violência, abusos 
e negligência constituem razões suficientes para encaminhar uma criança para instituição de abrigo ou, quando recorrentes, para a adoção legal definitiva.

O processo de adoção está diretamente relacionado com a realidade das instituições de abrigo, afinal, é o local responsável pelo cuidado total da criança ou do adolescente, enquanto este aguarda decisão judicial sobre sua possível adoção. Constitui o ambiente no qual a criança pôde receber os cuidados e o afeto necessários ao seu desenvolvimento ou, então, o local onde fomentou sentimentos de mágoa e rancor pelas situações vividas anteriormente ou pelo tratamento recebido na própria instituição. Apesar de algumas conquistas significativas neste âmbito, observa-se, que pouco se evoluiu no que tange à construção de uma nova realidade, um novo sentido para as instituições de abrigo. Ainda, para Carvalho (2002), o contingente de crianças entregue à adoção tende a aumentar significativamente em decorrência da crescente pauperização da população de baixa renda e, por isso mesmo, merece uma atenção especial por parte dos administradores públicos. Lane (1995) assinala a ineficiência de grande parte das instituições de abrigo na sua função de proporcionar às crianças condições favoráveis de desenvolvimento. A autora afirma que as instituições de abrigo tendem a reproduzir as condições de sofrimento e abandono já vividas por essas crianças e adolescentes em suas experiências anteriores à vida na instituição. No entanto, seria insensato e acrítico generalizar essa premissa para a totalidade de instituições de abrigo, já que cada instituição representa uma situação peculiar. Desse modo, não é possível desconsiderar as muitas exceções que fogem a essa caracterização.

Outros autores, como Arpini (2003), delegam uma importância fundamental da instituição de abrigo para o desenvolvimento infantil. Esta autora afirma que é necessário que a sociedade repense a instituição como um local possível de desenvolvimento pleno da infância, onde a criança pode encontrar referenciais identificatórios positivos. Para tanto, é necessário que a própria instituição seja reestruturada no contexto de um novo cenário social no qual as crianças institucionalizadas não sofram com o preconceito e com a marca do estigma que o viver ou o ter vivido em instituições implica ainda hoje.

Segundo autores como Reppold (2003), Puretz e Luiz (2007), Costa e Ferreira (2007) e Camargo
(2005), durante muito tempo a prática da adoção veio a contemplar os interesses dos pais adotivos. Casais que não podiam ter filhos, que perderam algum filho ou que se sentiam solitários com a saída dos filhos de casa, recorriam à adoção de uma nova criança como meio de suprir uma falta, uma necessidade. À criança adotada cabia uma posição de resignação, pontuada de uma "gratidão necessária" pela oportunidade que estavam recebendo e pela perspectiva de um "futuro melhor". Assim, ainda é frequente a tendência de associar a adoção à caridade, bondade e atitude filantrópica. Entretanto, atualmente, exige-se um olhar mais abrangente sobre a adoção, de modo que esta prática favoreça o desenvolvimento pleno do adotado, uma vez que já teve seu passado marcado por muitos sofrimentos e privações.

Legalmente, visando o benefício da criança, elege-se um rol de características que uma família deve apresentar para, a partir do processo avaliativo, ser considerada habilitada à adoção. Costuma-se dar prioridade a casais, unidos legalmente, com um tempo razoável de matrimônio, com condições financeiras de abarcar um novo integrante na família e cujo lar deixe transparecer uma atmosfera de equilíbrio emocional e afetivo entre seus membros. Além disso, há a exigência de que a diferença de idade entre adotantes e adotados seja de, no mínimo, 16 anos. Esses critérios foram encontrados por Costa e Campos (2003) em avaliações psicossociais de famílias candidatas à adoção. Analisando, mesmo sem muito rigor, é possível antever que o perfil da família candidata à adoção que atende às exigências legais corresponde ao perfil de família nuclear, ainda hoje, o modelo mais comum e considerado o ideal para um "bom desenvolvimento".

Família, por si só, já constitui uma categoria de difícil conceituação. No decorrer de toda a história, o ser humano vem desenvolvendo diferentes formas de configuração familiar, condizentes com as condições de existência próprias de cada momento histórico. De acordo com Reis (2001), a família nuclear é resultado da consolidação do sistema capitalista e o estudo da história dessa configuração familiar é muito elucidativo no sentido de compreender as raízes desse tipo de organização familiar, cuja estrutura e funções receberam contornos de "natural" e "universal". O modelo familiar nuclear se apresenta como o ideal de família mais consoante com os interesses das 
classes dominantes e assim o foi desde a emergência do sistema capitalista. Percebe-se na família nuclear burguesa uma grande valorização da privacidade e da domesticidade, necessárias à constituição do "homem burguês", autônomo e autodisciplinado.

Quando abordada a questão do perfil dos candidatos a filho adotivo, verifica-se que há uma maior procura por bebês saudáveis, do sexo feminino e de cor clara. Costa e Campos (2003) salientam a dificuldade de colocação das crianças mais velhas, afro-descendentes e/ou com problemas de saúde. Observa-se, por parte das famílias postulantes à adoção, uma importância muito grande delegada à compatibilidade entre os perfis da criança e da família adotante. Vargas (1998) assinala que tal preocupação emerge como tentativa de prevenir eventuais surpresas com o novo integrante da família. Muitas vezes, é depositada na criança adotada uma gama de expectativas, fruto de uma construção erigida no imaginário da família adotante, o que incute no filho adotivo a necessidade premente de corresponder a tais expectativas. Contudo, essa autora enfatiza a importância de um trabalho de preparação, de aproximações graduais, que podem levar a uma integração da família sonhada, idealizada, com a família real, possível.

Nesse contexto, cabe investigar os eventuais motivos que impulsionam a adoção de uma criança que já se aproxima da adolescência. Há grande consenso por parte dos estudiosos em definir a adolescência como um período de transição, quase sempre marcado por ambivalência, crises e conflitos. Cabe, aqui, pensar a condição de sujeitos institucionalizados que estão passando por uma série de transformações e conflitos decorrentes da adolescência e que não dispõem de um suporte familiar que os sustente e os ampare nesse período de transição. Muitas vezes, a instituição abarca e dá conta de assumir esta responsabilidade. No entanto, o que se verifica é um grande contingente de adolescentes que passou a infância aguardando uma possível adoção que não se concretizou. É inegável que ainda existe muito preconceito e resistência à adoção de crianças maiores e adolescentes.

Ebrahim (2001) acredita que o fato da criança ser mais velha não constitui um elemento inviabilizador da adoção e que sua idade e trajetória não afastam substancialmente a possibilidade de integração bem-sucedida numa família adotiva. Essa especificidade é chamada de adoção tardia, expressão largamente utilizada para designar a adoção de crianças maiores de dois anos de idade. Entretanto, a própria expressão "tardia" é revestida de preconceito na medida em que pressupõe que haja uma idade "ideal" para que alguém seja adotado. Sendo assim, essa expressão, assim como muitos outros termos, apresenta-se como uma verdadeira "armadilha", já que situa a adoção e seus envolvidos num campo ideológico que demarca fortes balizas entre a "oportunidade" de adoção e o perfil requerido para que esta se efetive. Esta é mais uma forma de segregar, de delimitar, e de cristalizar a crença de que somente bebês ou crianças muito pequenas podem ser adotadas. Ebrahim (2001) atenta, ainda, para a necessidade de desmitificar os preconceitos em torno da criança mais velha que está à espera da adoção, em prol do maior incentivo à prática desse tipo de adoção. Os resultados de suas pesquisas na área levam esse autor a concluir que a adoção de crianças que já ultrapassaram a segunda infância não prejudica seu processo de adaptação à nova família e que as possíveis dificuldades não diferem qualitativamente das encontradas por crianças adotadas quando bebês ou por filhos biológicos. Em qualquer um dos casos, deve-se primar pelo estabelecimento de relações entre pais e filhos que possibilitem a construção de laços afetivos sólidos, objetivando o bem-estar de todos os envolvidos no processo de filiação.

A questão das crianças e adolescentes abandonados e/ou vítimas de negligência ou maus-tratos acolhidos em instituições de abrigo constitui uma problemática merecedora de atenção especial. Quando afastada a possibilidade de regressar ao convívio da família de origem, esses sujeitos institucionalizados ficam à espera de uma eventual adoção, a qual ainda se caracteriza como um processo penoso, marcado por trâmites burocráticos exaustivos. Quando bem sucedida, a adoção provoca, inevitavelmente, mudanças significativas na estrutura funcional da família adotante que recebe um novo integrante, com um modo de ser próprio e solidificado, com hábitos e costumes peculiares, que o caracterizam com um ser singular, muitas vezes, diferente dos demais membros da família adotante.

Diante da importância da temática, pretendese desenvolver o presente estudo no sentido de se buscar compreender quais elementos compõem 
a iniciativa da adoção de crianças/adolescentes com esse perfil. Caracterizam-se, portanto, como objetivos do trabalho investigar quais são as principais motivações que impulsionam a adoção de um adolescente, como se dá esse processo para a família que adota e qual é o perfil tido como o ideal para a família candidata à adoção. Investigar como se dá o processo de adoção desses indivíduos que já estão entrando na adolescência, a partir da ótica da família adotante, possibilita a compreensão das principais motivações que levam a família a optar por esse tipo de perfilhação. Essa maior compreensão das motivações pode contribuir no sentido de incentivar essa prática, uma vez que a maioria dos casais prioriza a adoção de bebês recém-nascidos. $\mathrm{O}$ modelo de família nuclear (pai, mãe e filhos) ainda é, na sociedade ocidental contemporânea, concebida como o ideal de família, como a "garantia" de um desenvolvimento "normal" e "estruturado". Tal prescrição é incutida ideologicamente no senso comum da sociedade e, assim, é compreensível o desejo de pertencimento a esse tipo de família. Nesse sentido, atenta-se para o sofrimento experimentado por aqueles que passam, em muitos casos, toda a infância e a adolescência esperando serem adotados por uma família nesses moldes.

Como aponta Ducatti (2003), é cada vez mais frequente o número de pesquisas em torno da adoção. Acredita-se que um estudo que aborde tais aspectos possa contribuir para uma maior produção acadêmica que instigue o aumento do interesse por esta área. Na perspectiva de que o conhecimento produzido academicamente se converte em benefício, ainda que de modo indireto, a essa população, acredita-se, portanto, que a presente pesquisa possua relevância, tanto na dimensão acadêmica quanto no âmbito social.

\section{Método}

A pesquisa foi iniciada somente após a aprovação do projeto pelo Comitê de Ética em Pesquisa com Seres Humanos da Universidade Estadual do Centro-Oeste (COMEP/ UNICENTRO - Protocolo $\left.\mathrm{n}^{0} 09752 / 2007\right)$, aval que salvaguarda a integridade dos participantes da pesquisa. $\mathrm{O}$ trabalho em questão consiste num estudo de caso, caracterizado pela coleta e registro de dados de um ou mais casos parti- culares. Segundo Chizzotti (1995), o estudo de caso retrata uma realidade específica, mas também revela uma infinidade de aspectos globais, comuns a diversos e diferentes participantes. Este autor atribui ao estudo de caso três fases distintas, a saber: a) a seleção e delimitação do caso; b) o trabalho de campo; c) a organização do relatório. Na presente pesquisa foi realizado o estudo de caso de duas famílias, cada qual com sua realidade peculiar, mas com a característica comum de terem adotado uma criança de onze anos de idade.

O presente estudo contou com a participação de duas famílias (Família A e Família B) que efetivaram a adoção de crianças que, na ocasião, já haviam ultrapassado a segunda infância. Ter adotado a criança ou adolescente há pelo menos dois anos foi o critério de escolha das famílias a serem entrevistadas. A Família A efetuou a adoção há mais de sete anos e a Família B realizou a adoção há aproximadamente seis anos. Optou-se por essa condição por se acreditar que, uma vez passada a fase inicial de adaptação, e consequente entrosamento e identificações mútuas que mantêm o novo integrante na família adotiva, caracteriza a adoção como bem-sucedida.

A Família A é composta do casal: ele, bombeiro de 35 anos, e ela, conselheira do Conselho Tutelar, de 33 anos, e um filho biológico, de quatro anos, além do filho adotado aos onze anos e que agora tem 18 anos. A Família B é formada por um casal: ele, professor universitário, 44 anos, ela, pedagoga, 41 anos, uma filha adotada há aproximadamente cinco anos, aos três meses de vida e hoje com 6 anos de idade, e ainda o filho adotado aos onze anos e hoje com 16. Como nos dois casos os irmãos eram crianças muito pequenas, as entrevistas foram realizadas apenas com os pais e com o adolescente adotado. Em virtude da dificuldade de encontrar, por meio de fóruns, famílias que correspondessem aos critérios da pesquisa e que estivessem dispostas a relatar suas experiências, o contato com os participantes se deu informalmente, através de conhecidos em comum. Via telefone, foi feito um primeiro contato com as duas famílias, a fim de apresentar os objetivos da pesquisa e convidá-los a participar. A entrevista com a Família A foi realizada em abril de 2008, e a com a Família B, em agosto do mesmo ano. Mediante a pronta disposição para participar da pesquisa, foram marcados os respectivos horários e locais. A Família 
A preferiu que a entrevista fosse realizada na casa de familiares, enquanto que a Família B designou como local a sala de conferências do hotel no qual estavam hospedados na cidade onde a entrevista foi realizada.

A entrevista utilizada foi a do tipo semiestruturada, com questões abertas que propiciam ao entrevistado liberdade para responder às perguntas como lhe conviesse. Bleger (1998) define como "aberta" a pergunta que pode exigir diversas palavras para a resposta, e "fechada" aquela pergunta que pode ser respondida com poucas palavras. Desse modo, as questões abertas têm um conteúdo descritivo e valorativo. Optou-se por este tipo de entrevista pela possibilidade de exploração de conteúdos explícitos e implícitos no discurso dos entrevistados. Com o consentimento prévio dos participantes, as entrevistas foram gravadas em aparelho eletrônico, próprio para este fim. Tal medida faz-se necessário para que não fossem perdidas informações importantes que poderiam não ser resgatadas pela memória após a entrevista e também por acreditar que as anotações simultâneas tendem a intimidar o entrevistado, mais que a gravação eletrônica.

As entrevistas foram realizadas em três momentos distintos. No primeiro momento, foram realizadas as entrevistas individuais com o pai e, depois, com a mãe. Num segundo momento, a entrevista foi dirigida simultaneamente ao casal. E, num terceiro momento, a entrevista foi aberta à participação do adolescente adotado, visando instigar o relato da experiência compartilhado e discorrido por toda a família. Já que nos dois casos estudados os irmãos eram menores de doze anos, prescindiu-se da participação deles. Tal procedimento foi desenvolvido desta maneira com o objetivo de verificar se há uniformidade de respostas entre o plano individual e o coletivo. Isso porque uma possível divergência nas respostas dá margem a uma investigação acerca das reais impressões e concepções de adoção, pelo viés de cada um dos envolvidos no processo, em respeito à sua singularidade.

As questões do roteiro de entrevista serviram de condutoras, a fim de que não se fugisse aos objetivos propostos inicialmente. Durante toda a entrevista, foi garantida aos entrevistados total liberdade para expressarem todas as suas impressões acerca do que cada pergunta, por ventura, suscitasse em sua subjetividade. Desse modo, as perguntas atuaram como norteadoras do assunto, possibilitando que a "conversa" contemplasse todos os objetivos. Durante a realização das entrevistas procurou-se propiciar uma atmosfera agradável, na qual os entrevistados pudessem se sentir o mais à vontade possível, pois a preservação da integridade dos entrevistados deve consistir num cuidado fundamental de qualquer pesquisa científica que envolva seres humanos.

O presente estudo consiste numa pesquisa qualitativa, que requer uma análise da mesma forma, qualitativa, realizada basicamente por meio da análise de conteúdo. De acordo com Martins e Bicudo (1994), a pesquisa qualitativa busca uma compreensão particular do fenômeno estudado, evitando, assim, as generalizações, tão comuns em pesquisas exclusivamente quantitativas. $\mathrm{O}$ foco da pesquisa qualitativa recai, portanto, no específico, no peculiar, no individual, visando sempre à compreensão e não à explicação de dado fenômeno humano. No que tange à análise de conteúdo, Richardson (1999) a define como um conjunto de técnicas que permitem a análise das informações obtidas através dos envolvidos na pesquisa. Esse processo se dá a partir de procedimentos sistemáticos e objetivos que possibilitam a descrição fidedigna do conteúdo das mensagens transmitidas. Esses procedimentos devem contemplar tanto o conteúdo explícito das mensagens quanto os conteúdos implícitos que demandam investigação e inferências.

Após a transcrição literal de todos os momentos das entrevistas, partiu-se para uma pré-análise, viabilizada por leituras flutuantes, a partir das quais foi possível verificar o que era recorrente nas falas dos entrevistados, o que era proferido com maior ênfase, o que era deliberadamente ocultado, o que era mais e o que era menos explorado. Enfim, buscouse identificar o que emergia de mais significativo das falas dos participantes das entrevistas. Pretendeu-se destinar um tratamento qualitativo às informações obtidas que incluísse uma análise cuidadosa e a exploração minuciosa dos conteúdos subjetivos disponíveis explícita ou implicitamente no discurso de cada entrevistado, em cada uma das modalidades de entrevista adotadas (individual, do casal e coletiva). A partir desses procedimentos de tratamento das informações obtidas, chegou-se ao seguinte conjunto de quatro categorias e suas respectivas subcategorias: 


\section{Motivações para a adoção}

Esta categoria refere-se ao conjunto de elementos que possivelmente contribuíram para a decisão do casal em adotar uma criança dessa faixa etária.

\subsection{Apego ao filho adotivo}

O forte apego ao filho antes da adoção foi constantemente atribuído como um dos elementos preponderantes para a decisão pela adoção.

\subsection{Cultura Familiar}

Nesta subcategoria encontram-se as motivações para adoção resultantes de uma cultura familiar e ou social que favorece e que estimula esta prática. biológicos

1.3 Impossibilidade/dificuldade de gerar filhos

A motivação para a adoção é atribuída direta ou indiretamente pela impossibilidade de o casal gerar filhos biológicos.

\subsection{Fé/religiosidade e predestinação}

Esta subcategoria inclui as falas que fazem referência à possibilidade de a adoção ter sido intermediada ou providenciada por entidades metafísicas, como a religiosidade e o destino.

\section{Processo de adoção}

Esta categoria inclui as percepções dos entrevistados em relação ao que vem a ser adoção, como se caracteriza e como se devem configurar as relações entre os envolvidos antes, durante e após o processo de adoção se efetivar e, ainda, o desenvolvimento do processo de adoção propriamente dito.

\subsection{Preconceito e falta de informação}

Engloba as representações de adoção atreladas a falsas crenças e preconceitos que, segundo os participantes, são resultantes da falta de informação.

\subsection{Processo de adoção e experiência pessoal}

Esta subcategoria concerne ao processo de adoção como um todo, tanto na dimensão legal, quanto no plano subjetivo, intrafamiliar. Também aqui ressaltam-se as alusões à experiência da adoção de uma criança mais velha, a partir do relato de cada um dos integrantes da família (individualmente, do casal e da família toda).

\subsection{Estratégias de elaboração}

Evidenciam-se algumas "estratégias" das quais os participantes se valeram para elaborar internamente o processo de adoção.

\section{O filho adotivo}

Nesta categoria encontram-se referências ao filho adotivo, suas qualidades, limitações, méritos e dificuldades, a partir das falas dos pais.

\subsection{Relação com o passado}

Este item tange à relação da família - pais e filho adotivo - com o passado deste filho. O que sabem, o que falam, o que fica subentendido e o que permanece oculto. A relação com o passado a que fazem menção diz respeito à família de origem ou à vida institucional anterior à adoção.

\section{A família}

Esta categoria alude às idiossincrasias das famílias adotantes entrevistadas, a partir de seu próprio ponto de vista, isto é, inclui o modo como se percebem enquanto família, nos diferentes momentos de sua história.

\subsection{Alterações na dinâmica familiar}

Salientam-se as transformações decorrentes da adoção, as implicações para a rotina familiar e os modos de enfrentamento dessa nova situação.

\subsection{Perfil da família adotante}

Nesta subcategoria encontram-se atributos e características elencadas pelos pais e mães entrevistados como indispensáveis à família que opta pela adoção. Esse rol de características, extraído de suas falas, possibilita o levantamento de um "perfil" da família postulante a esse tipo de adoção.

\section{Resultados e discussão}

As entrevistas realizadas com as famílias participantes desse estudo de caso nos permitem inferir que, nas duas situações investigadas, a adoção de uma criança de onze anos representou 
uma experiência ímpar para todos os integrantes da família. Tal experiência possui muitos vieses e desdobramentos que, ora aproximam um caso do outro, ora os distancia em virtude da singularidade de cada realidade específica. A primeira categoria "Motivações para a adoção" faz menção diretamente ao principal objetivo do trabalho, que se refere à investigação do que leva um casal a optar pela adoção de uma criança mais velha que, inclusive, já se aproxima da adolescência. Nos dois casos investigados, os pais atribuem a decisão pela adoção ao forte apego que estes desenvolveram quando dos primeiros contatos com o futuro filho, nas respectivas instituições das quais provieram. Isso fica evidente nas falas dos pais: "Quando o conheci eu já me apaixonei... acho que o que levou realmente a gente a adotar foi ter visto... ter conhecido ele, é uma coisa assim, de coração” (Mãe, Família A). E: "Eu acho que a gente foi se apegando muito no moleque (risos), já não tinha mais jeito" (Pai, Família B).

Uma possível compreensão sobre esta forte ligação que une pessoas pode ser pensada pelo viés da Teoria do Apego, desenvolvida pelo psicanalista John Bowlby (1907-1990). Ribas e Moura (2004), partindo dos pressupostos básicos desse autor, definem apego como uma disposição, uma abertura para aproximar-se de uma pessoa em específico. As relações de apego se desenrolam externamente, mas partem necessariamente de estados internos. Nas crianças este tipo de disposição para a proximidade em relação ao outro mostra-se muito claramente, à medida que elas demonstram sua necessidade de vivenciar relações interpessoais que lhe transmitam segurança afetiva. Nessa perspectiva, as interações entre a criança e seus cuidadores são regidas pela necessidade que o pequeno sujeito sente de apegar-se a um outro que lhe sirva de continente e de referência.

Embora nas duas famílias os pais tenham afirmado que a motivação maior para que a decisão de adotar se concretizasse tenha sido o apego à criança, suas falas nos permitiram identificar outras possíveis motivações, não menos importantes. No caso da Família A, a cultura familiar (família da mãe) certamente estimula a adoção, já que faz apologia aos benefícios dessa prática. São muitos os casos de parentalidade adotiva na respectiva família, fato muito recorrente na fala do casal. Segundo eles, em razão disso, formou-se e propagou-se, no interior dessa organização familiar, a cultura de adotar crianças e de considerar isso natural e até mesmo esperado. Foi possível observar que este casal atribui à cultura familiar uma causalidade em relação à motivação para que se efetivasse a adoção.

Outra implicação importante para a tomada de decisão em relação à adoção, não explicitada como tal mas identificada na fala dos pais entrevistados, foi a impossibilidade ou dificuldade de gerar filhos biológicos. Nas duas famílias entrevistadas esses aspectos da pré-história do casal constituíram, segundo nossas inferências a partir de suas falas, o elemento desencadeador da ideia de adotar alguém. Na Família A, a ideia de adoção surgiu logo após um aborto espontâneo que abalou o casal. Já no caso da Família B, a adoção está relacionada diretamente à impossibilidade de o casal gerar filhos biológicos. Esta condição que atravessa, de certo modo, a história das duas famílias entrevistadas, figura como uma das mais recorrentes motivações para a adoção. Costa e Ferreira (2007) concluem, a partir de um levantamento de pesquisas já realizadas sobre a adoção, que não ter filhos próprios é o principal mote que impulsiona a prática da adoção. A adoção condicionada à impossibilidade de gerar filhos biológicos configura uma tomada de decisão ainda muito calcada na visão tradicional sobre a adoção, que prioriza os anseios dos pais adotantes, em detrimento dos direitos plenos impetrados pelas crianças nas últimas décadas. Para Ebrahim (2001), a adoção motivada pela infertilidade, atitude tão arraigada na sociedade brasileira, justifica a procura acentuada por bebês. Camargo (2005) assinala que grande parte dos candidatos a adotantes recorre à prática da adoção na tentativa de "resolver um problema, preencher uma lacuna e contribuir para a resolução de um luto [...]" (CAMARGO, 2005, p. 5).

Além dos elementos já citados, a féreligiosidade ou predestinação também são evocadas nas falas dos pais das duas famílias entrevistadas. Nesse sentido, de acordo com eles, a adoção parece ter sido resultado da providência divina ou constituir uma bela surpresa do destino, como se os meninos tivessem sido "colocados em seu caminho" e que isso já estaria programado de alguma maneira, por alguma entidade: "Essas coisas são de Deus [...] Foi um encontro... eu acho que foi uma coisa que tava predestinado" (Pai, Família A). E: "Agradeço 
muito a Deus por ter colocado ele na nossa vida..." (Pai, Família B). Num estudo sobre a avaliação psicossocial de famílias candidatas à adoção, Costa e Campos (2003) também encontraram o papel que os futuros pais adotivos atribuem ao acaso e ao divino. Percebe-se, portanto, que esta é uma alternativa comumente procurada pelas pessoas, de um modo geral, em especial pelas que possuem uma educação atrelada a fundamentos religiosos. Recorrer a explicações sobrenaturais pode aliviar tensões e ansiedades, pode justificar ou legitimar determinadas atitudes e posicionamentos e consiste numa via de expressão de sentimentos e emoções que deve ser considerada como uma dimensão importante e elucidativa, inclusive no processo de adoção.

As inúmeras motivações para a adoção de crianças consideradas mais velhas constituem uma questão ampla e controversa que suscita muitos vieses e incita muito debate. Ebrahim (2001) aponta como uma das principais motivações para esta prática o conjunto de características da personalidade dos postulantes à adoção. Para este autor, maturidade emocional e altruísmo são traços que favorecem a adoção de crianças maiores ou adolescentes. Trata-se de uma possibilidade de análise não explorada diretamente nas entrevistas, mas que em outros estudos apresentarem importantes conclusões, revelando sua validade e pertinência. Esta questão, entretanto, não pode ser esgotada num trabalho desse porte. De qualquer maneira, as discussões em torno dessas possibilidades de análise enriquecem o conhecimento já erigido sobre a temática e instigam novas pesquisas.

A segunda categoria levantada, "Processo de adoção", revela como os entrevistados concebem e entendem a adoção e como transcorreu o processo nos seus casos específicos. Para eles, existe claramente um perfil da família que deseja adotar, especialmente crianças mais velhas, o que será abordado mais detalhadamente na categoria 4. Todos, em algum ou em alguns momentos, fazem alusão à questão do preconceito que reveste o tema da adoção e que, em certa medida, cerceia o incentivo à prática. As crenças errôneas a respeito da adoção advêm, em sua opinião, de visões distorcidas, das quais acreditam estar livres. Consideram-se pessoas esclarecidas sobre o assunto, que possuem uma representação clara sobre adoção e suas particularidades. Sob sua ótica: "No Brasil não tem essa cultura... quer ado- tar, mas tem ser bebezinho, tem muito preconceito com a adoção tardia, o que é uma pena" (Mãe, Família A). Costa e Ferreira (2007) reiteram os medos e temores que permeiam a adoção de crianças consideradas mais velhas. As crenças de que a criança sempre virá com uma bagagem de "maus hábitos", que pode comprometer sua adaptação à nova família bem como seu desenvolvimento futuro, são tomadas como uma verdade absoluta e, muitas vezes, afastam a ideia da adoção de crianças com tal perfil. A isso Vargas (1998) denomina temor da hereditariedade patológica do filho adotivo. De acordo com Ebrahim (2001), a pré-suposta dificuldade na educação dessas crianças e adolescentes é mais um dos argumentos utilizados pelos candidatos a pais adotivos para justificar a preferência por bebês. Esses candidatos alegam que crianças nessas condições já têm iniciado seu processo de socialização e de estruturação psíquica, o que levaria hipoteticamente a resistirem à imposição de novos padrões de comportamento e de conduta. Em consequência, a adoção de crianças que já não são mais bebês é pouco difundida no país, favorecendo, assim, as adoções internacionais e/ou fomentando os já altos índices de crianças institucionalizadas.

A mídia é um dos maiores propagadores de ideias e de conceitos e, consequentemente, de preconceitos e formulações distorcidas da realidade. De acordo com Puretz e Luiz (2007), nossa concepção de adoção, portanto, em muito reflete o senso comum da sociedade, abundantemente alimentado pelos veículos de comunicação, com destaque à televisão. Estas autoras consideram que o alcance e o poder de influência da mídia como formadora de opinião são inegáveis. Desse modo, qualquer mudança na maneira de conceber a adoção e de lidar com esta forma alternativa de afiliação deve também passar, necessariamente, pelos veículos de comunicação de massa. Campanhas e aparições de casos (reais ou fictícios) menos caricatos e destituídos de preconceito, que só faz alimentar os medos e temores em relação à adoção, podem constituir um arsenal importante na construção de um olhar mais revestido de alteridade, respeito e disponibilidade, ideia também compartilhada por Costa e Campos (2003). Talvez este seja um recurso profícuo na tentativa de diminuir a disparidade e os desencontros existentes entre as duas grandes filas que colocam em lados opostos 
os maiores interessados em adoção: a fila de homens e mulheres à espera de uma criança que corresponda ao perfil requerido por eles para a adoção e, na contramão, a fila de crianças e adolescentes adotáveis à espera de uma família que os adote, que os afilie.

Diante das críticas que sofreu quando da adoção de um menino de onze anos, a mãe da Família B assinala: "Eu acho que para adotar não tem idade, não tem uma época que pode adotar e outra que não pode ou que não é adequado [...]". Esta afirmação corrobora o questionamento necessário acerca da expressão adoção tardia, que carrega, mesmo que implicitamente, a prescrição de que existe uma idade ideal para a adoção, anterior aos dois anos de vida. A mãe da Família A expõe sua percepção de que os bebês que são entregues à adoção e que não são imediatamente adotados, permanecem na instituição, inevitavelmente crescem, galgam fases do desenvolvimento, muitos deles, inclusive, chegando à adolescência sem nunca terem vivido a experiência da adoção. O pai da Família B pontua que, no seu caso específico, os preconceitos em torno da adoção de um menino de onze anos partiram, inclusive, de representantes do sistema judicial envolvidos nos processos de adoção. Isso se deve ao fato de que vivemos numa sociedade que ainda valoriza exacerbadamente os laços consanguíneos e a condição biológica de parentalidade. Para Costa e Ferreira (2007), tal característica influencia na construção da maternidade e da paternidade adotivas que, em geral, buscam se aproximar, ao máximo, do modelo de família baseado em vínculo consanguíneo. Camargo (2005) e Costa e Campos (2003) também acreditam que vivemos ainda o paradigma biologicista que propala o laço sanguíneo como condição essencial à constituição familiar, o que prejudica a construção de uma cultura que prestigie a adoção. Para Camargo (2005) faz-se necessário romper com esses entraves paradigmáticos que só dificultam o estabelecimento de um novo olhar, mais flexível e que contemple o direito que a criança possui e que está assegurado pelo Estatuto da Criança e do Adolescente de ser cuidada, amparada e protegida. Para ele, no Brasil há a convergência suficiente para promulgação de uma sentença implacável que delega à criança abandonada apenas dois caminhos possíveis: o abrigo ou a rua.

Entretanto, de acordo com Costa e Ferreira (2007) assistimos surgir no país uma nova cultura que procura uma família para crianças em vez do tradicional movimento de buscar crianças que correspondam às exigências e expectativas da família adotante. Nessa perspectiva, a adoção de crianças que já se aproximam da adolescência integra o conjunto de "adoções modernas", "atípicas" ou "necessárias", como nos apontam Puretz e Luiz (2007). Essa nova forma de pensar e de viver a adoção demanda um perfil específico que “[...] pressupõe uma família que aceite o diferente, a alteridade, que não só lide com projetos de filiação alternativos, mas que efetivamente adote o diferente" (COSTA; FERREIRA, 2007, p. 3). Para Ebrahim (2001), atualmente tem se difundido o que ele chama de uma "cultura da adoção" que visa precipuamente à colocação da criança, que por uma forte razão foi privada do convívio com a família de origem, numa família substituta que a acolha num processo de afiliação. Camargo (2005) ratifica que se trata de um processo de passagem da "adoção clássica", que prioriza a satisfação das necessidades da família adotante para a "adoção moderna" que coloca a criança no papel protagonista do processo adotivo. No entanto, este mesmo autor salienta que no Brasil ainda prevalecem as "adoções clássicas", que preconizam os interesses dos pais adotivos, cenário no qual a criança ou adolescente atua como mero coadjuvante.

Ainda que veladamente, as famílias entrevistadas, especialmente a Família B, entendem a adoção também como uma maneira de dar uma oportunidade a alguém cujo destino seria incerto. A Família B sugere que a instituição familiar (modelo tradicional, nuclear) salvaguarda a criança de maiores dificuldades e problemas, garantindo certa segurança e provimento afetivo. Conforme salientam Costa e Campos (2003), esse tipo de fala pode revelar um senso humanitário que também é comumente identificado como uma das motivações para adoção de crianças maiores.

No tocante à experiência da adoção, as duas famílias entrevistadas consideram-na positiva e enriquecedora: "[...] tanto quanto um filho natural, a adoção é uma coisa fantástica” (Pai, Família A). "Eu acho nossa história muito bonita [...] A experiência que tirei de tudo isso é valiosa, indico a adoção tardia para todo mundo" (Mãe, Família A). O filho também se refere à experiência de ter sido adotado: "Eu faria tudo de novo..." (Filho, Família A). De 
acordo com a segunda família entrevistada: "É uma coisa maravilhosa que aconteceu na nossa vida [...] é uma experiência maravilhosa, é ser pai e ser mãe, só que mais rápido que uma gestação". (Pai, Família B). A mãe complementa: "É uma experiência muito gratificante, muito boa" (Mãe, Família B). Ducatti (2003) afirma que o que propicia uma experiência satisfatória de adoção é a disposição dos envolvidos, especialmente da família adotante, para a administração dos conflitos que eventualmente surgirem, a abertura para o novo e para o diferente, e principalmente a construção de um desejo em torno da afiliação de um novo integrante. Isso garante que filhos, adotivos ou biológicos, sejam inseridos numa linhagem, uma vez que esse é um movimento impetrado pela função simbólica e não genética.

No que concerne ao processo de adoção, as falas indicam que, nos dois casos estudados, o processo em termos legais foi rápido, sem maiores delongas. No plano subjetivo, as duas famílias afirmaram que, apesar de ser uma fase de adaptações mútuas, o processo de adoção transcorreu de modo tranquilo e relativamente rápido. Como aponta a mãe da Família A: "Ele tinha o direito de não gostar de nós, de não se adaptar a nós. A adaptação era dele, cabia a ele gostar ou não de nós." Esse olhar é imprescindível ao sucesso da adoção, uma vez que, consoante com Costa e Ferreira (2007), nessa modalidade de adoção, a criança interage mais ativamente que um bebê, posicionando-se nesse processo de construção do amor filial-parental. O filho da Família A, discorrendo sobre as etapas que antecederam sua adoção, conta que realizou diversas visitas aos futuros pais antes de ser adotado: "Se eu fosse morar com eles, já sabia como era a base, já fui conhecendo a família que eu iria pertencer." Essa declaração ilustra bem a afirmação anterior de que, diferentemente do bebê, a criança maior se posiciona ativamente no processo, também avalia, formula juízos, reivindica, negocia, enfim, também adota (ou não) a família adotante. Além disso, ela possui uma história de vida pregressa, anterior à adoção, que não deve, de modo algum, ser negligenciada. Na segunda família entrevistada encontramos, de acordo com suas falas, uma situação semelhante à Família A. Para o casal, o processo foi rápido e também sem grandes dificuldades: "O processo judicial foi rápido e tranquilo e o processo de adaptação foi assim, mais gradual... de lá pra cá tem sido maravilhoso" (Mãe, Família B).

Costa e Ferreira (2007) afirmam que a adoção dita tardia resulta de um movimento contínuo de identificação e estranhamento, estando sujeita a conflitos e tensões. Desse modo, os pais adotivos tendem a encontrar mais dificuldades que os pais biológicos no tocante à construção da maternidade e da paternidade. Nos casos das duas famílias entrevistadas, estas dificuldades não foram acentuadas a ponto de prejudicar o processo de adoção. A literatura pesquisada dá destaque a experiências conflituosas, marcadas por dificuldades. Ebrahim (2001), referindo-se às pesquisas sobre a temática desenvolvidas ou em andamento no Brasil, ainda são em número muito reduzido. Segundo este autor, a literatura que existe frequentemente alude a casos clínicos que geralmente levam à associação da adoção a problemas e fracassos. Assim, cabe refletirmos sobre as histórias bem-sucedidas a fim de entendermos como se processa a adoção nesses casos e o que os difere das situações difíceis, mais comumente encontradas.

De fato, o processo de adoção abrange uma dimensão legal e uma construção subjetiva. Como afirma o pai da Família B: "O processo, a espera, tudo isso foi, pra nós, como uma gravidez que tava se desenvolvendo." Nesse sentido, é possível constatar que a formação de vínculo é gradual, demanda abertura, disponibilidade e disposição. Costa e Ferreira (2007) assinalam que o parentesco, nos casos de adoção, é engendrado, construído e não imposto, sendo desenvolvido em prol da efetiva filiação do novo integrante no grupo familiar.

Assim como em qualquer outra situação nova, a adoção requer um processo de elaboração, de processamento que propicie que as mudanças desencadeadas pelo ingresso de um novo integrante na família não acarretem prejuízos ou danos para nenhum dos seus membros. Dessa maneira, todos os envolvidos encontram formas de trabalhar a nova situação, no sentido de dar conta de entender o que está acontecendo e de superar eventuais dificuldades. Curiosamente, na Família A, identificamos formas bem sutis de trabalhar a questão da adoção de um menino de onze anos, em relação à família, à sociedade, ao filho adotivo e a eles próprios. Percebe-se que a adoção é considerada natural por eles e, por meio de "brincadeiras", esta naturalização é transmitida ao menino 
e ao seu entorno social, ao mesmo tempo em que atua como um mecanismo de elaboração psíquica do evento. "Nem gosto de usar esse termo "adotivo", às vezes eu até sinto em ter que falar para as pessoas, ele do meu lado e tal, aí eu brinco e digo que ele é o meu filho que tava perdido por aí e que eu peguei ele grande já para evitar trocar fralda, é eu brinco... trabalho dessa forma..." (Pai, Família A). De fato, Rosa (2008) salienta que o que é necessário é que a criança ou o adolescente seja acolhido, de fato, pela família adotante. É imprescindível que esse filho seja inscrito na história da família, a qual deve prover uma atmosfera que propicie o desenrolar de uma narrativa, compartilhada por todos os seus integrantes. A construção coletiva de uma narrativa própria da família favorece a elaboração dos conflitos, de ansiedades e de temores, e que, a partir de um novo capítulo, com novos personagens, possibilita a sequência dessa história que não cessa de ser reescrita e vivida.

Outra estratégia considerada pelos pais entrevistados como essencial para o sucesso da adoção é a questão da transparência e do diálogo aberto em torno da situação de adoção: "No caso da adoção, tudo tem que ser registrado, tudo tem que ser falado. Não se pode esconder nada, tudo tem que ser transparente, muito claro, uma coisa muito bem resolvida, discutida pra tudo dar certo..." (Mãe, Família A). Costa e Ferreira (2007) concordam que esta é uma condição que muito contribui para uma efetiva vinculação da criança à nova família.

[...] os pais devem favorecer oportunidades de conversa com a criança sobre seu passado, de modo aberto e não defensivo, auxiliando-a a construir narrativas sobre ele [...]. Desta forma, a criança preenche lacunas de tempo ou de situações não compreendidas, com o auxílio de pessoas significativas para ela e afetivamente envolvidas com o seu bem estar. (COSTA; FERREIRA, 2007, p. 19).

A questão do silêncio em torno do passado é muito comum nos casos de adoção. Este é um dos principais elementos que colocam a adoção na posição de tabu, que relega a história pregressa da criança a um ostracismo inexorável. Assim, parece haver um acordo tácito, traduzido em esforço mútuo para manter esse passado enterrado, um assunto não tocado, que incute na criança ou adolescente adotado a interdição em relação à sua própria história. Para Ebrahim (2001), muitas famílias optam pela adoção de bebês justamente pela possibilidade de esconder da criança seu passado, suas origens, garantindo, assim, a conservação da áurea de "segredo" que circunda muitos casos de adoção.

Não raro, as crianças adotadas na segunda infância ou na adolescência ingressam na família adotante e logo percebem que, embora lembrem exatamente de sua história pregressa, não podem tocar nesse assunto, admitindo-o como um tabu. Rosa (2008) alerta que: "O não dito é sempre mais desestruturante que a verdade, seja ela qual for." (p. 10). $\mathrm{Na}$ ausência da verdade, abre-se espaço para que o vazio seja sentido mais intensamente pelo sujeito, além de induzir a exacerbação de fantasias a respeito de suas origens. As lacunas resultantes desse processo de "não-ditos" dificultam ou até inviabilizam a construção de uma identidade integrada.

$\mathrm{Na}$ terceira categoria trabalha-se a questão do filho adotivo, de como este foi recebido e o que representa para os pais. Suas falas deixam transparecer um total entrosamento, evidenciada por elogios constantes ao filho. A vinculação da criança ou adolescente à família adotiva pode ser difícil quando há histórico de abandonos e/ou perdas significativas e pode tender a ser estabelecida rápida e intensamente, em virtude do estado de fragilidade e carência em que se encontram muitas dessas crianças/adolescentes. O modo como se estabelecem os laços entre família adotante e o novo filho vai depender substancialmente das experiências anteriores de ambos os lados e da maneira como este filho é acolhido por esta nova família. Neste processo o filho adotivo pode desenvolver diferentes estratégias contra a perda virtual do amor de sua nova família, uma vez que a possibilidade de devolução se mantém ainda presente no início. A mãe da Família A relata que o filho demonstrava muito medo de ser devolvido, porque, de alguma forma, tinha-lhe sido incutido a ideia de que deveria ser um "filho perfeito" para que a devolução não acontecesse.

Rosa (2008) assinala que, nessas circunstâncias, a criança ou adolescente teme perder o amor conquistado e, por isso, muitas vezes resiste em deixar-se envolver por esse amor, por essa afeição. Em outras situações, o filho adotivo pode tomar um posicionamento mais ativo, mostrando-se independente, capaz de virar-se por conta própria. Como podemos observar nas falas dos pais da Família 
A: "Um menino, além de tudo, independente, se vira com tudo em casa, nunca tivemos problema de dependência" (Pai, Família A). "Ele cozinha muito bem, ele me ajuda, não tem preguiça, ele me ajuda muito nas atividades domésticas" (Mãe, Família A). Essa atitude pode revelar uma proteção, uma defesa contra outro possível abandono ou como uma forma de provar a si próprio e aos demais que possui recursos psíquicos próprios para lidar com uma eventual frustração.

Ainda nessa categoria, julgamos interessante explorar a relação da família adotante com o passado do filho adotivo. Nas duas famílias, a maioria das referências ao passado concerne ao período em que os meninos viveram nas casas de abrigo, antes de serem adotados. Quanto ao passado anterior à instituição, na família de origem, a Família A discorre mais detalhadamente, enquanto que a Família B não faz alusão à família de origem do filho, talvez por desconhecer essa pré-história, uma vez que o menino vivia na instituição de abrigo desde bebê. Quanto ao passado do filho da Família A, os pais esclarecem: "Ele lida bem com a história dele, sempre deixei claro para ele, 'você não é diferente de ninguém, você só tem uma história de vida diferente" (Pai, Família A). A mãe, referindo-se à família de origem do filho: "A mãe dele está viva. Ela (a mãe biológica) não queria abandonar ele, eles acabaram se separando por circunstâncias da vida, mas não por falta de amor, ou maus-tratos."

E quanto ao ambiente institucional, identificamos a percepção de que as respectivas famílias versam sutilmente sobre as instituições de abrigo: "O clima ali dentro dessas instituições é assim bem triste..." (Mãe, Família A). "Essas crianças (de instituições de abrigo) se apegam bastante, são muito carentes, precisam muito de carinho. Eu acho que o fato de ele ter vivido tanto tempo no orfanato, sem pais, nem mãe, fez com que ele amadurecesse muito cedo, a gente cria formas de se defender no mundo, quando precisa. Imagine como é que fica o psicológico de uma pessoa que é abandonada pelos pais e que tem que viver numa instituição, onde sempre, a gente sabe, tem um monte de crianças que necessita de atenção, de cuidados ao mesmo tempo..." (Pai, Família B).

O filho da Família B fala sobre sua vida anterior à adoção: "Eu já tinha pensado tanto em ter uma família quando eu morava lá no orfanato... lá era bom, mas eu via na televisão, também quando ia lá alguma família visitar as crianças eu ficava imaginando como devia ser essa coisa de ter uma casa, um pai, uma mãe...”. Provavelmente, durante o tempo que antecedeu a adoção, este adolescente criou a imagem de uma família idealizada, fomentando expectativas e fantasias. Para Rosa (2008). é comum e até esperado que isso ocorra. No entanto, a família geralmente idealizada como "perfeita" passa por um necessário processo de desidealização. O importante é que essa desidealização, no encontro com a família real, não resulte numa desilusão. A nova família deve proporcionar ressignificações, a reescritura de uma história que não parou de se desenrolar com a adoção, tendo apenas continuidade com essa novidade. Tratase de uma via com duas mãos: de um lado, a família deve integrar o filho ideal com o filho real; de outro, o filho adotivo precisa integrar a família idealizada com a família real, concreta.

A partir das falas dos entrevistados, constatamos que as duas famílias demonstram manter uma relação harmoniosa com o passado, tanto familiar quanto institucional, do filho adotivo. No entanto, conforme assinalam Puretz e Luiz (2007), a preferência da maioria dos postulantes à adoção por bebês recém-nascidos pode ser entendida como uma tentativa de anular o passado do filho(a). Fantasiosamente, esses pais imaginam estarem adotando uma criança sem história, o que supostamente possibilitaria que começasse a se escrever a história desse pequeno sujeito a partir da adoção, como num segundo nascimento. Isso evitaria o confronto com muitas questões que são suscitadas pela adoção, especialmente em relação aos pais biológicos. Fantasias, como a de perder o filho para os seus progenitores, são frequentes em pais adotivos, que, não raro, estabelecem uma relação de rivalidade, simbólica ou real, com os primeiros. Esse tipo de fantasia amedronta a família adotante, alimenta certos mitos em torno adoção, inibindo, em muitos casos, a sua prática. Costa e Campos (2003) ressaltam o papel dos trabalhadores do Poder Judiciário na melhor elaboração e integração entre o passado e o presente da criança ou adolescente adotivo. Cabe a esses profissionais: "Obter e manter todas as informações pertinentes à origem e história 
de vida do adotando-adotado a fim de que este possa reconstruir sua história [...]." (COSTA; CAMPOS, 2003, p. 225).

A última categoria - "A família" - explora aspectos relacionados à dinâmica familiar como um todo. As falas dos entrevistados salientam que as mudanças na organização da família foram inevitáveis com a chegada de um novo integrante. Embora não tenha havido uma preparação inicial quanto à chegada do filho adotivo, por esta ter sido uma decisão repentina, a Família A assinala que, a partir do momento em que a decisão foi tomada, o casal sentiu a necessidade de se reorganizar, em função da vinda de um menino de onze anos, o qual passaria a ser seu filho. Nesse caso particular, o casal não tinha outros filhos, sendo que a dinâmica daquela família contava apenas com o homem e a mulher, a partir da adoção, pai e mãe. De casal passaram a pais de um menino em vias de entrar na adolescência. Porém, suas falas evidenciam as mudanças como decorrentes do ingresso de um novo integrante, não enfatizando o fato de este ter onze anos de idade.

Para a Família B, as transformações mais incisivas advieram da filha, adotada cerca de um ano antes do filho. Ela foi adotada aos três meses de vida e, segundo seus relatos, a adoção de um bebê que carecia de muitos cuidados e de assistência integral, representou muito mais em termos de mudanças que a adoção de um adolescente. "[...] a mudança muito maior foi com a chegada da L., quando o P. chegou a gente já estava mais acostumado com a ideia de ser pai e mãe..." (Mãe, Família B). As transformações provocadas pela vinda do filho adolescente foram mais no sentido de mudança na rotina, já que o menino já tinha uma vida social, organizada em compromissos e tarefas que já lhe eram delegadas ou confiadas. A literatura consultada privilegia os casos em que a adoção representou problemas de adaptação mútua. Costa e Ferreira (2007), ao acompanharem famílias durante os primeiros meses de adoção de crianças maiores, depararam-se com situações de inadaptação, dificuldade de relacionamento e entrosamento, tanto dos pais em relação aos filhos adotivos, quanto dos filhos em relação à nova família. Autores, como Ebrahin (2001), ressaltam o temor de que a criança ou adolescente não se adapte ao que a família impõe como atributos de sua educação, a partir da adoção. No senso comum, há a convicção distorcida de que na adoção, de um modo geral, o filho adotivo só pode se adaptar à família adotante após um processo árduo e penoso para todos.

Ainda nessa última categoria, os pais entrevistados elencam um rol de características que consideram imprescindíveis a uma família que deseja adotar uma criança ou um adolescente. A Família A salienta o fato de que os pais não devem entender a adoção como um gesto de caridade, na medida em que, ao seu ver, essa prática beneficia muito mais a quem adota. "Normalmente as pessoas adotam para satisfazer desejos seus. Não adotamos ele para ajudar, ele é quem nos ajuda..." (Pai, Família A). Observamos que os discursos das duas famílias são consoantes com a nova concepção de adoção, atualmente vigente. Ebrahim (2001), ao estudar famílias que efetivaram esse tipo de adoção, chega à seguinte hipótese: "Supõe-se que as pessoas que adotam crianças maiores são mais altruístas, maduras e estáveis emocionalmente" (p. 3). No entanto, o próprio autor pondera que tais características podem contribuir, mas não podem ser tomadas como condições que impediriam quem não as possui de realizar esse tipo de adoção com sucesso.

O perfil de família adotante levantado, ainda que indiretamente, pelos entrevistados condiz com o modelo nuclear (composto de pai, mãe e filhos), mas apresenta especificidades. Costa e Campos (2003) trazem importantes contribuições para a compreensão do perfil de família adotante. Trata-se de um perfil pautado num conjunto de características que nos remetem à família nuclear, composta por pai, mãe e filhos (preferencialmente biológicos). Para estas autoras, a grande maioria de famílias que procuram a adoção, inclusive de crianças consideradas mais velhas, buscam se aproximar ao máximo da parentalidade biológica. Nos dois casos estudados não foi possível identificar esforços neste sentido, até porque querer assemelhar-se ao máximo ao padrão consanguíneo significa negar as especificidades que balizam fortemente a afiliação adotiva.

Um ponto que chama a atenção é o fato de que os dois casais discorrem sobre as qualidades imprescindíveis aos postulantes à adoção e se percebem como detentores de tais atributos. Suas falas são pontuais ao definirem homens e mulheres que se dispõem a esse tipo de adoção como pessoas esclarecidas, livres de preconceitos, altruístas e abertas, 
identificando-se com este perfil e "percebendo-se" dessa forma. Para eles, o casal que estiver disposto a adotar um adolescente deve, necessariamente, estar aberto a esse novo contexto e a todas as implicações decorrentes. Essa abertura inclui uma relação transparente com a história anterior do filho adotivo, uma educação calcada em princípios morais e uma posição de pais que não permite espaço para um tratamento diferenciado do novo integrante que denote pena ou extrema rigidez.

As duas famílias dão ênfase à educação que os pais devem prover aos filhos, adotivos ou biológicos. Costa e Ferreira (2007), em sua pesquisa com pais adotantes, identificam muito presente a preocupação com a responsabilidade de ser um bom "encaminhador", de dar bom exemplo, que repercuta positivamente na formação do caráter da criança adotada: "Tem que educar, ensinar o que é certo, o que é errado, tudo isso é uma grande responsabilidade..." (Mãe, Família B). "É tudo uma questão de formação, de educação." (Pai, Família B). Parece tratar-se de um compromisso assumido pelos pais adotivos de orientar e conduzir o desenvolvimento da criança, a fim de inseri-la num padrão de comportamento condizente com as características peculiares da família adotante.

\section{Considerações finais}

A partir da análise dos aspectos mais relevantes que emergiram das entrevistas à luz do referencial teórico que fundamenta e sustenta o presente artigo, é possível fazer algumas considerações acerca da temática abordada e de sua ressonância no cotidiano de pessoas comuns. Os dois casos trabalhados desvelam realidades muito semelhantes no tocante à experiência de adoção de um adolescente. Os casais exortam esse tipo de adoção e não cessam de ressaltar os benefícios dessa prática para todos os envolvidos, em especial para os pais adotivos. No entanto, devemos salientar que essas duas situações denotam o sucesso, nem sempre alcançado por quem se aventura nos meandros dessa modalidade alternativa de paternidade e mater-nidade. Talvez a pronta disposição das famílias em participar da pesquisa esteja relacionada ao fato de que o que tinham para relatar evidenciaria uma adoção bemsucedida.
Contudo, as realidades encontradas nos intrigaram no sentido de transparecerem uma atmosfera de total entrosamento com o filho adotivo e encantamento pela ideia da adoção, quando o que mais abundantemente se encontra na literatura são relatos de fracassos, inadaptações e dificuldades. Esta ênfase no insucesso nos levou a pensar nas situações em que tudo decorre satisfatoriamente e conflui para uma afiliação efetiva. Por que razão casos bem-sucedidos não são tão abordados, discutidos e divulgados? Parece haver um esforço, por parte da sociedade, em cristalizar as falsas crenças sobre a adoção de adolescentes, a fim de manter esta prática isolada e pouco difundida, relegando-a ao estatuto de "tardio". E nesse movimento de manter o status quo segue-se negando o diferente, a alteridade. Em relação a esse processo de negação e de reprodução do mesmo, a academia pode e deve exercer papel preponderante de rompimento com tal ideologia e de construção de novos sentidos em torno da adoção. Daí a importância de produções científicas que instiguem, que provoquem, que questionem ou que simplesmente denunciem as transformações que urgem.

A realização da presente pesquisa confirmou que, de fato, em torno da adoção atuam muitos tabus e preconceitos, constituindo uma temática permeada de silêncios, de não-ditos, revestida de segredos impermeáveis. A maior dificuldade encontrada foi justamente em encontrar famílias dispostas a participar, sendo que a maior barreira no contato com famílias com esse perfil foi imposta justamente pelo meio jurídico que lida diretamente com o acompanhamento dos processos de adoção. Isso nos levou a refletir sobre como esse tipo de posicionamento contribui para que a adoção ainda seja tão rechaçada e tão negada enquanto modalidade de afiliação distinta da biológica. Os profissionais que, pressupõe-se, sejam mais esclarecidos e influentes, devem repensar constantemente sua prática, a fim de que não representem apenas meros instrumentos a serviço da ideologia dominante. Reitera-se a relevância do trabalho de preparação e de acompanhamento dos casos de adoção realizado pelos profissionais engajados nessas atividades. O psicólogo não pode ficar indiferente a essa questão e deve ser aquele profissional que oferece uma escuta atenta, que acolhe e que se preocupa 
em atender pessoas, muito mais que apenas cumprir uma tarefa que lhe é delegada.

Como já exposto anteriormente, a literatura sobre a temática da adoção de adolescentes ainda é muito escassa. A adoção de grupos de irmãos, de crianças negras, portadores de doenças crônicas são temáticas que merecem também uma atenção especial por parte dos pesquisadores, no sentido de incentivar e favorecer esse tipo de prática. Diante de todas as questões problematizadas, finaliza-se esta breve reflexão com uma indagação: Se uma adoção realizada quando a criança tem idade inferior a dois anos é considerada precoce e, a partir dessa faixa etária, tardia, qual seria o momento certo de adotar alguém? As famílias entrevistas nos revelaram que não existe uma idade ideal para adotar, mas sim que o momento certo é o momento da adoção, aconteça ela em qualquer fase do desenvolvimento. O que vai garantir o sucesso de uma adoção é a disposição de todos os envolvidos para aceitar e, de fato, receber o diferente, assumindo-o como tal.

\section{Referências}

ARPINI, D. M. Repensando a perspectiva institucional e a intervenção em abrigos para crianças e adolescentes. Revista Psicologia Ciência e Profissão, Brasília, DF, ano 23, n.1, p.70-75, 2003.

BLEGER, J. Temas de psicologia. São Paulo: Martins Fontes, 1998.

BÖING, E. CREPALDI, M.A. Os efeitos do abandono para o desenvolvimento de bebês e a maternagem como fator de proteção. Revista Estudos de Psicologia, Campinas, SP. v.21, n.3, p.221-226, 2004.

CAMARGO, M. L. A adoção tardia no Brasil: desafios e perspectivas para o cuidado de crianças e adolescentes. In: SIMPÓSIO INTERNACIONAL DO ADOLESCENTE - ADOLESCÊNCIA HOJE: DESAFIOS, PRÁTICAS E POLÍTICAS,1. 2005, São Paulo. Anais... São Paulo: Faculdade de Educação da Universidade de São Paulo, 2005.

CARVALHO, A. M. Crianças institucionalizadas e desenvolvimento: possibilidades e desafios; In: CARVALHO, A. M. A.; KOLLER, S. H.; LORDELlO, E. R. (Orgs.). Infância brasileira e contextos de desenvolvimento. São Paulo: Casa do Psicólogo, 2002.

CHIZZOTTI, A. Pesquisa em ciências humanas e sociais. 2 ed. São Paulo: Cortez, 1995.

COSTA, L. F.; CAMPOS, N. M. V. A avaliação psicossocial no contexto da adoção: vivências das famílias adotantes. Revista Psicologia: teoria e pesquisa. Brasília, DF, v.19 n.3 p.201-310. 2003.

COSTA, N.R.A.; FERREIRA, M.C.R. Tornar-se pai e mãe em um processo de adoção tardia. Revista Psicologia: Reflexão e Crítica. Porto Alegre. v.20 n.3, p.425-434. 2007.

DUCATTI, M. A tessitura inconsciente da adoção. São Paulo: Casa do Psicólogo, 2003.

EBRAHIM, S. G. Adoção tardia: uma visão comparativa. Revista Estudos de Psicologia. Campinas, SP, v. 18, n. 2. p.29-40 maio-ago. 2001

LANE, S. M. A mediação emocional na constituição do psiquismo humano. In: SAWAIA, B. (Orgs.). Novas veredas da psicologia social. São Paulo: Brasiliense, 1995.

MARTINS, J.; BICUDO, M. A. V. A pesquisa qualitativa em psicologia - fundamentos e recursos básicos. 2 ed. São Paulo: Editora Moraes, 1994

PURETZ, A.; LUIZ, D.E.C. A adoção tardia: desafios e perspectivas na sociedade contemporânea. Revista Emancipação (UEPG). Ponta Grossa, PR, p.298-323, 2007.

REIS, J. R. T. Família, emoção e ideologia; In: CODO, W.; LANE, S. T.M. Psicologia Social: o homem em movimento. São Paulo: Brasiliense, 2001.

REPPOLD, C. T. Reflexão social, controle percebido e motivações à adoção: características psicossociais das mães adotivas. Revista Estudos de Psicologia. Natal, RN, v.8 n.1, p.25-36 jan-abr. 2003.

RIBAS, A.F.P.; MOURA, M.L.S. Responsividade materna e Teoria do Apego: uma discussão crítica do papel de estudos transculturais. Revista Psicologia Reflexão e Crítica, Porto Alegre, v.17, n.3, p.315-322, 2004.

RICHARDSON, R. J. et al. Pesquisa social: métodos e técnicas. 3 ed. São Paulo: Atlas, 1999.

ROSA, D.B. A narratividade da experiência adotiva fantasias que envolvem a adoção. Revista Psicologia Clínica, Rio de Janeiro, v.20 n.1, p.97-110, 2008.

VARGAS, M. M. Adoção tardia: da família sonhada à família possível. São Paulo: Casa do Psicólogo, 1998. 